OPEN ACCESS

Edited by:

Milton D. Cox,

Miami University, United States

Reviewed by:

Irwin King,

The Chinese University of Hong Kong,

China

Mark Andrew Pegrum University of Western Australia,

Australia

${ }^{*}$ Correspondence:

Angel Lu

angellu@cityu.edu.hk

Specialty section:

This article was submitted to Digital Learning Innovations,

a section of the journal

Frontiers in Education

Received: 30 October 2020

Accepted: 22 March 2021

Published: 12 April 2021

Citation:

Lu A, Wong CSK, Cheung RYH

and Im TSW (2021) Supporting Flipped and Gamified Learning With

Augmented Reality in Higher Education. Front. Educ. 6:623745.

doi: 10.3389/feduc.2021.623745

\section{Supporting Flipped and Gamified Learning With Augmented Reality in Higher Education}

\author{
Angel Lu' ${ }^{1 *}$, Crusher S. K. Wong', Richard Y. H. Cheung ${ }^{2}$ and Tarloff S. W. Im $^{3}$ \\ ${ }^{1}$ Office of Chief Information Officer, City University of Hong Kong, Kowloon, Hong Kong, ${ }^{2}$ Department of Chemistry, \\ City University of Hong Kong, Kowloon, Hong Kong, ${ }^{3}$ Office of the Education Development and Gateway Education, \\ City University of Hong Kong, Kowloon, Hong Kong
}

Chemistry education is challenging when many students cannot see the relevance and interest between what they learn at school and their everyday life outside the curriculum. Due to the prevalence of chemicals in real life, students lose interest in those not-so-novel Chemistry problems as they are satisfied with their rudimentary grasp of knowledge. Therefore, it is of paramount importance to draw students' attention to those day-to-day Chemistry concepts, a task in which augmented reality (AR) can be a competent pedagogical facilitator. Despite its popularity due to the development of smart devices, educators are still averse to adopting AR in teaching because of the doubts about its pedagogical effectiveness and difficulties in implementation. This paper will demonstrate an AR app developed by City University of Hong Kong (CityU) for a year four undergraduate Chemistry course under two UGC's project funds and CityU's Teaching Development Grant that aligns with the university's Discovery and Innovationenriched Curriculum. The learning theories and technology stack of development and deployment will be shared in this paper. The consideration during preparation, production, and publishing will also be documented. A pilot survey about students' perception of the AR showed positive feedback for the AR app in terms of enhancing awareness, learning, understanding, and engagement, which addresses the concerns of retaining students' engagement during teaching and learning real-life Chemistry. We hope that educators who are interested in adopting AR can gain insights from this AR development experience. This research can act as a foundation for further exploration of applying AR in secondary and tertiary Chemistry education.

Keywords: augmented reality, AR, AR learning design, hazardous chemicals, environmental toxicology

\section{INTRODUCTION}

City University of Hong Kong (CityU) is one of the pioneers in the adoption and application of virtual reality (VR) technology in creative art, humanities, and social sciences (Im et al., 2018; Wong et al., 2019). Inspired by the previous design of a smartphone app developed for a CityU MOOC (Ip et al., 2016) and based on the previous development experience of web-based VR field trips (Wong et al., 2019), this AR chemistry software, "Chemicals in our Environment: Friends or Foe," is intended to apply AR technology to strengthen students' understanding of the toxicants and to 
ensure the fulfillment of the intended learning outcomes through its gamified environment in a flipped-classroom approach.

Information on microscopic chemistry can be too abstract for students to grasp (Behmke et al., 2019) because of the unobservable behaviors of chemicals and the potential conflicts of learners' daily experience from chemical sciences (Limniou et al., 2008; Bower and Jong, 2020). The chemical composition of products, potential problems of the environmental toxicants, and their fate in the environment can be a formidable task for students to digest. As a result, students become oblivious and lose interest in learning about chemicals in real life. However, an understanding of chemical and scientific ideas is important for dealing with problems of everyday life in a technological society (Childs et al., 2015), so chemistry educators need to convey the importance and relevance of the subject to learners and society (Karukstis and van Hecke, 2003). With high relevance for creative inquiry, teaching, and learning, AR is an emerging technology expected for broad adoption in education (Wu et al., 2013; Johnson et al., 2016) because of its potentiality of improving learner interaction, motivation, and enjoyment (Akçayır and Akçayır, 2017). However, the pace of VR and AR development goes beyond research into the pedagogical application, which results in the insufficient evidence base for educators to determine the "why" or "how" of using VR and AR in learning and teaching (Bower and Jong, 2020). These concerns accentuate the need for further research of VR and AR learning method and tools used in STEM teaching and learning. This paper addresses AR's pedagogical concerns and its effectiveness by documenting the best practice of developing the AR tool and conducting a pilot study.

\section{A Brief Review of Augmented Reality Applications in Teaching and Learning}

Augmented reality (AR) is the technology that blends digital information dynamically with real-world environments to engage users by in-time interaction with virtual objects (Azuma, 1997). Milgram et al. (1995) explained that AR and VR are rooted in the same concept but with a different user level of immersion on two sides of the Reality-Virtuality (RV) continuum. One side of the RV continuum, generally regarded as VR, consists entirely of computer-generated or synthetic objects to construct an immersive environment for users. In contrast, AR augments a real-world scene with stimulated cues for users to interact. Guttentag (2010) defined AR as the enhancement of a real-world simulation adopting layers of computer-generated images.

Pence (2010) identified two AR methods, marker-less AR and marker-based AR. The former method suggests mobile devices correspond to virtual information via users' GPS location function. In contrast, the latter means users retrieve virtual details with their mobile devices or tablets by scanning the marked AR code. Cheng and Tsai (2013) categorized AR into imagebased AR and location-based AR. In image-based AR, virtual information is obtained through actual picture recognition to conduct mobile learning without any geographical limitation. Location-based AR is designed to facilitate the discovery of augmented information around the target spots by detecting users' location and position.

In light of the recent advancement in computing development, $\mathrm{AR}$ is made more affordable for the public and education applications. A myriad of AR research and implementations in education indicate that the recognition of its advantages over traditional classroom teaching and media communication, such as PowerPoint, images, and videos, is gaining momentum (Yung and Khoo-Lattimore, 2019). Sotiriou and Bogner (2008) advocated that the application of $\mathrm{AR}$ adds value to science learning by increasing students' experimentation and interest. The relevancy of science can be made more feasible and fruitful with immersive technology (Wang and Hannafin, 2005). Students can more readily understand challenging concepts in science due to AR's remarkable ability to visualize details and hidden information (Yoon et al., 2017). Threedimensional visualization, supported by AR, can offer a contextual and personal learning experience. This positive learning experience can help learners make sense of phenomena and connect science ideas by applying the new knowledge to the current and other situations (Joe, 2015). Zhang et al. (2014) created a mobile AR app for outdoor astronomical observations and interactive learning. They accorded that mobile devices' portability and free geographical operations were the main success factors. Furthermore, they included data derived from learners' mobile device functions and sensors to engage them in stargazing outdoors. AR implementations for elementary students were also designed with elements like accomplishing missions, storytelling, and mini-games to simulate game-based learning and encourage students to have fun (Squire and Jan, 2007; Chen and Tsai, 2012; Koutromanos and Styliaras, 2015).

The use of AR in school settings has been supported by several researchers as a positive indication for improving learners' self-efficacy (Lin and Chen, 2015), critical thinking (Chao et al., 2016), cognitive load, and motivation (Cheng, 2016). Kurilovas (2016) supported that AR-based systems effectively enhance student satisfaction and motivation compared with traditional teaching. From a systematic review on science, technology, engineering, and mathematics (STEM) learning with AR, Ibáñez and Delgado-Kloos (2018) agreed that the application of AR fits the instructional techniques of the flipped classroom. The flipped classroom is intended to facilitate outclass learning at the preliminary levels so that class time can be used for active learning and discussion. The traditional flipped classroom approach is through multimedia learning content, like the video (Hwang et al., 2015). However, Jensen (2011) suggested that students are more likely distracted in taped learning outside the more structured classroom environment, undermining learners' attention and engagement during the flipped learning. Therefore, the success of flipped learning depends significantly on how the out-class learning activities can encourage students' engagement and exploration (Lo, 2018). Research indicates that AR can enhance learners' motivation by offering immediate feedback and relevant learning content (Tosti et al., 2014). In the study by Chang and Hwang (2018), AR-based flipped learning yielded positive results in 
learners' performance by encouraging students to interact and practice more.

\section{Learning Theories and Instructional Design in AR Software}

Sommerauer and Müller (2018) summarized the most prevalent learning theories in educational AR design from a cognitive or constructivist perspective.

Cognitivists regard learning as a process to receive, organize, store, and retrieve information in the brain (Sommerauer and Müller, 2018). The effectiveness of one's learning process depends on his processing (Craik and Lockhart, 1972), suggesting that memory will last longer by a more profound process of information, and existing knowledge structure will determine one's attention to perceive, learn and remember (Woolfolk and Hoy, 2006). The cognitive learning theory (CLT) by Sweller (2011) proposed that learners' total cognitive load is limited, so the increase of unfavorable intrinsic and extraneous cognitive load will undermine learners' germane resources for attention and organization of learning materials. Since the intrinsic cognitive load, depending on the complexity of the instructional topic which may not be altered by instructors (van Merriënboer and Sweller, 2005), and the extraneous cognitive load, associating with the presentation of learning materials under the control of instructors, are additive and cannot exceed the capacity of working memory (Fred et al., 2004), instructional designers have to reduce extraneous cognitive load which does not contribute to learning so as to foster an increase of germane load within learners' overall working memory (van Gog et al., 2010). Therefore, the presentation of learning materials has a profound impact on reducing extraneous cognitive load. Sweller and Chandler (1994) recommended integrating correlated textual and visual information to reduce learners' mental efforts to synthesize information, helping them understand complex concepts. The cognitive theory of multimedia learning (CTML) proposed by Mayer (2009), which was partially applied in this research (Table 1), made a hypothesis that the works of mind bring more meaningful learning. CTML, based on cognitive science principles of learning, suggests three assumptions, namely: (1) the dual channels, visual and verbal, of human information processing system, (2) the limited processing capacity of each channel, and (3) the active cognitive process for knowledge construction. Therefore, instructional design to reduce irrelevant content, as advocated by CTML, is expected to reduce the extraneous cognitive load of learners and promote effective learning by increasing their germane resources.

Constructivism believes that learning is an active process of knowledge acquisition rather than passive receiving (Kundu et al., 2017). It is usually regarded as learner-centered learning because of its focus on learners' problem-solving strategies through information, resources, and social interaction (Woolfolk and Hoy, 2006). Lave (1991) emphasized that learning shall consist of mastering knowledge and tasks in realistic situations. Abdoli-Sejzi and Bahru (2015) supported that AR allows students to develop new knowledge and understanding via active interactions with the natural and context-rich virtual environments, which is aligned with constructivist ideas of education (Martín-Gutiérrez et al., 2010). Constructivists emphasize the importance of actively engaging students by creating a meaningful context that motivates them to construct knowledge based on their experiences because learning should be imposed by individuals rather than existing independently in the world (Dede, 2008). By applying AR in education to increase attention, satisfaction, and confidence (Khan et al., 2019), educators can help learners achieve a deeper level of engagement for lasting connections within their own knowledge (Kerawalla et al., 2006).

Game-based learning (GBL), widely applied in AR education research, resonates with the constructivist approach. GBL can transfer contextually relevant information in an immersive game environment more readily to real-life applications (Brom et al., 2010). It has been regarded as an effective and engaging method for learners (Eck, 2006) to connect their knowledge tightly with the physical and social worlds (Gee, 2008). Pedagogically, AR GBL can foster an experiential learning environment to convert boring instruction into a more entertaining experience (Lu and Liu, 2015). Learners are motivated to maintain positive learning behaviors (Kiili, 2005) which are positively correlated with deep learning and higher-order thinking (Crocco et al., 2016). We also adopted GBL in our design, which is likely to make learning experiences motivational and fun (Kiili, 2005; Hirumi et al., 2010; Crocco et al., 2016). In the AR Chemistry software, students are required to explore and handle the misplaced elements. Such gaming elements, inside the AR context, are expected to result in a more engaging learning experience to foster organic connections between the learning materials and the real world (Shirazi and Behzadan, 2013).

Principles for mobile learning from Herrington et al. (2009) were also incorporated into our design because of its mobility

TABLE 1 | Partial features adapted from 12 principles of CTML by Mayer (2009).

\begin{tabular}{|c|c|c|}
\hline Principle & Definition & $\begin{array}{l}\text { Implementation in the } \\
\text { AR app }\end{array}$ \\
\hline $\begin{array}{l}\text { Spatial contiguity } \\
\text { principle }\end{array}$ & $\begin{array}{l}\text { Students learn better when } \\
\text { corresponding words and } \\
\text { pictures are presented near } \\
\text { rather than far from each } \\
\text { other on the page or screen } \\
\text { (P.135) }\end{array}$ & $\begin{array}{l}\text { Cues with guiding texts ar } \\
\text { prepared on the same } \\
\text { screen as activities }\end{array}$ \\
\hline $\begin{array}{l}\text { Temporal contiguity } \\
\text { principle }\end{array}$ & $\begin{array}{l}\text { Students learn better when } \\
\text { corresponding words and } \\
\text { pictures are presented } \\
\text { simultaneously rather than } \\
\text { successively (P. 153) }\end{array}$ & $\begin{array}{l}\text { Pictures/videos and } \\
\text { narrations are presented } \\
\text { simultaneously }\end{array}$ \\
\hline $\begin{array}{l}\text { Segmenting } \\
\text { principle }\end{array}$ & $\begin{array}{l}\text { People learn better when a } \\
\text { multimedia message is } \\
\text { presented in user-paced } \\
\text { segments rather than as a } \\
\text { continuous unit (P. 175) }\end{array}$ & $\begin{array}{l}\text { The app is divided into } \\
\text { three separate scenarios }\end{array}$ \\
\hline Voice principle & $\begin{array}{l}\text { People learn better when } \\
\text { the narration is spoken in a } \\
\text { human voice rather than in } \\
\text { a machine voice (P. 242) }\end{array}$ & $\begin{array}{l}\text { Human voice-overs are } \\
\text { recorded for videos }\end{array}$ \\
\hline
\end{tabular}


and portability for AR learning. The importance of such mobility and portability has been heightened when physical classes are suspended under the COVID-19 pandemic. It is essential to engage students in online lessons or remote learning by allowing access to learning content whenever or wherever at their own pace. The first-hand interaction with the surrounding environment, supported by mobile AR, increases learners' motivation, making learning more situated, personal, and lifelong (Naismith et al., 2004). The portability and convenience of mobile learning are the overriding factors to remedy technologies' affordances and mediate knowledge construction and consumption of knowledge (Herrington et al., 2009). To further facilitate students' independent learning, ARbased flipped learning was adopted to promote positive learning attitudes, better learning performance (Chang and Hwang, 2018), enhancing students' attention (Röhl et al., 2013), and augmenting student engagement (Kobayashi, 2017). Since the AR software in the study is a pre-class activity immersing students in a virtual three-bedroom flat setting, students are engaged to learn about their home environments. The teacher will encourage students to bring the abstract concepts of misplaced toxic chemicals to their real home environments and construct other novel sets of AR scenarios with mishandled chemicals. Students will then form into groups in class to conduct mini-research about the hazardous chemical of their choice and share their findings with their peers to gain further insights and experiences in a reflection and discussion session.

\section{DEVELOPMENT OF AR}

There are three AR design stages, which consider factors relating to hardware, software, and content (Figure 1). All these factors are inter-related with each other in the AR application.

\section{Preparation}

In order to design a comprehensive framework, design elements applied by previous researchers were incorporated into the design after a review of the literature. Those elements have to be based on well-established standards to cover both internal and external communication in and from the AR app for both user and object communication.

After identifying the foundation of learning theories, several AR toolkits were evaluated based on their offered functions and limitation. Although plane detection in ARCore from Google and ARKit from Apple works well to detect vertical and horizontal surfaces, the libraries do not provide backward compatibility before Android version 26 and iOS11, respectively. To cover a wide variety of students' phones, Vuforia was picked because it allows a platform-neutral implementation of the function in general smartphones with cameras. Using Vuforia, we replaced platform-specific plane detection with image recognition, presenting the same idea of displaying the AR apartment model. Unity AR by Unity Technologies, which is the status-quo 3D game development platform, was finally selected because of cross-platform requirement, which is essential for our goal of Bring Your Own Device (BYOD) during online learning, as well as the availability of integration to XCode and Android Studio, which are the most common integrated development environments (IDEs) for iOS and Android. One of the features of Unity $3 \mathrm{D}$ is to translate code directly to $2 \mathrm{AR}$ languages for Apple iOS and Google Android. While Blender, an open-source $3 \mathrm{D}$ creation suite, was used to optimize the $3 \mathrm{D}$ model to enhance the performance of the AR software.

Meetings with the teacher and the subject experts were documented to confirm the AR software flow with relevant virtual objects (chemicals in a domestic setting), presented as layers of computer-generated images for simulation to align with the intended learning outcomes. Four chemicals, namely butane gas canister, formaldehyde, sulfuric acid, and carbon monoxide, together with four complete sets of scenarios, were selected to keep the project manageable while facilitating the learning objectives. Each chemical would be accompanied by a scenario, similar to a hotspot that involved a short static animation delivering its background to students, leading to a mini-game and other learning activities. The static animation and chemical items were drawn manually or modified from Shutterstock's selected graphics, a prepaid licensed footage library. The static images and scenes were processed through Adobe Illustrator. The background information of the household chemical was scripted and voiced over. Based on the design principles and learning theories, these chemicals were hidden and placed wrongly in the AR so that students will have to relocate them to avoid potential hazards through the given cues and hints. Such gaming elements and real-life simulation experiences were expected to engage and encourage students to explore the AR-powered app.

\section{Production}

During the production stage, graphic user interface (UI) elements, i.e., icons, buttons, and animation movement, were crafted by Adobe Illustrator and Adobe Photoshop to provide clear indicators to reduce learners' cognitive loads when using the AR software. For typical 3D models, we collected the 3D model references from an open-source 3D model platform, Sketchfab. However, those models could only act as prototypes because of the lack of optimization or the insufficiency of features. By using Blender to reduce polygons, modify details, map, and assign texture materials, those models could yield better performance, in terms of bootstrap time and physical storage volume, in the AR software. While being programmer-agnostic, Unity offers intuitive application programming interfaces (APIs) and a software development kit (SDK) to allow cross-platform mobile development.

Chemical items, interactive and gesture control, AR image recognition, and game logic of the software were programmed during this stage. The entire workflow of the AR app is illustrated below (Table 2). Students will begin by exploring the three-bedroom flat with objects surrounded by a thin layer of green illuminating light to prompt students to trigger a scenario to learn about the chemical's background. The 3D apartment model can be zoomed in and out and rotated with two fingers touching the mobile phone or tablet's screen. When a scenario ends, students will be asked to find the misplaced hazardous chemical in the household. Once the 


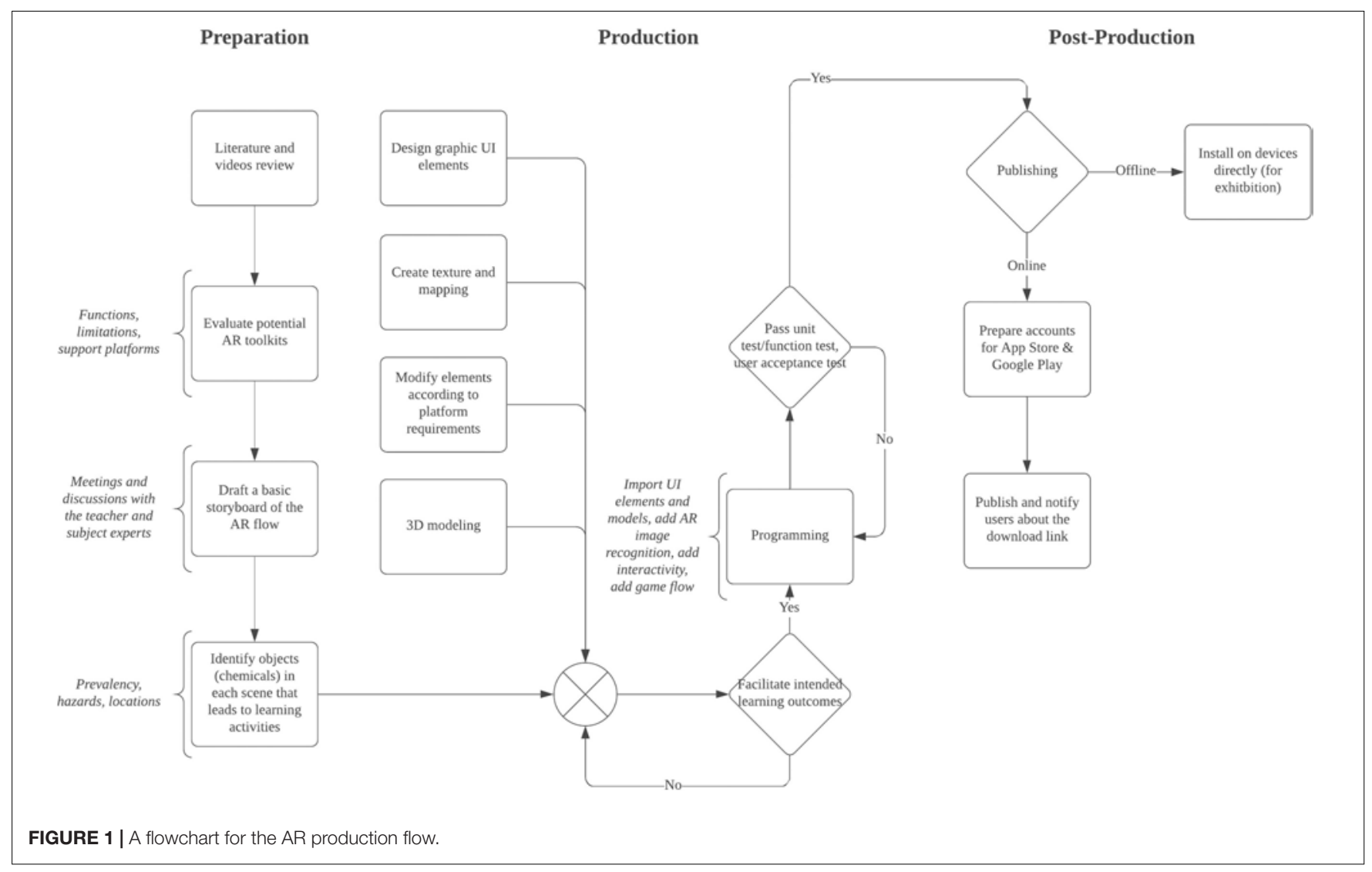

chemical is identified, there is another short static animation that explains the chemical's property. Students are then asked to handle the chemical correctly by placing it in an appropriate location, similar to a mini-game. In order to encourage and motivate students to find the hidden chemicals, digital badges indicating success will be awarded if the hazardous chemical can be found in $5 \mathrm{~min}$. If the chemical hunt exceeds the time limit, a highlight of the hidden chemical will be displayed. Besides, informative pages are added to supplement the background knowledge of the chemical after the chemical item is identified in order to facilitate the acquisition of the learning outcomes. The final step in the production was the reiteration based on functional tests, focusing on individual functions, and user acceptance test (UAT), for cosmetic errors or system testing to validate the end-to-end business flow of the AR app.

\section{Post-production}

After passing the validation and the tests, the AR app was ready to be published, either publicly or internally. The advantages of online publishing are the ease of installation by end-users through the existing app stores of their platform, as well as broader exposure of the software. However, the registrations and compliances required by the app stores may be complicating for an internal app intended for only a few dozen students in a Chemistry course. Therefore, we chose to publish internally by providing an APK package for the Android platform and an internal link to iOS users. Such an arrangement provided fast iterations of upgrade and bug fixing before the commencement of learning activities.

\section{FLIPPING A CLASS WITH AR SOFTWARE}

The AR tool is intended to facilitate students' online self-learning. By reading through self-learning materials in the app before classes, students are free to review unfamiliar topics according to their understanding or at their own pace. This pre-class preparation before the online face-to-face session not only allows the teacher to spend class time in a more meaningful way but also strengthens students' comprehension and ensures the fulfillment of the intended learning outcomes. After completing the tasks within the AR software, the teacher will elaborate on the potential hazards in the surrounding environment and ask the learners to form groups to consolidate their knowledge by constructing extra scenes of hazardous chemicals in the household. The exchange of ideas and collaboration is expected to strengthen students' understanding as teams of students are required to conduct a mini-research and presentation.

\section{DATA ANALYSIS AND FINDINGS}

This paper adopted quantitative methods to analyze students' feedback on the AR software. A questionnaire taken from 
Cai et al. (2014), which had been used to measure students' attitudes toward an AR Chemistry software, was distributed to 46 students of the Chemistry class after using the software. The questionnaire adopts a six-option Likert scale, ranging from "Strongly Disagree" as 1 to "Strongly Agree" as 6 for four constructs about learning attitude (7 questions), satisfaction within the AR software (14 questions), cognitive validity (5 questions) and cognitive accessibility (4 questions). An optional open-ended question asking for students' comments about the AR software was included at the end of the survey. 37 valid responses out of 46 were received within 2 weeks after the learning activities. To evaluate if the adopted questionnaire

TABLE 2 | An example of a complete AR workflow.
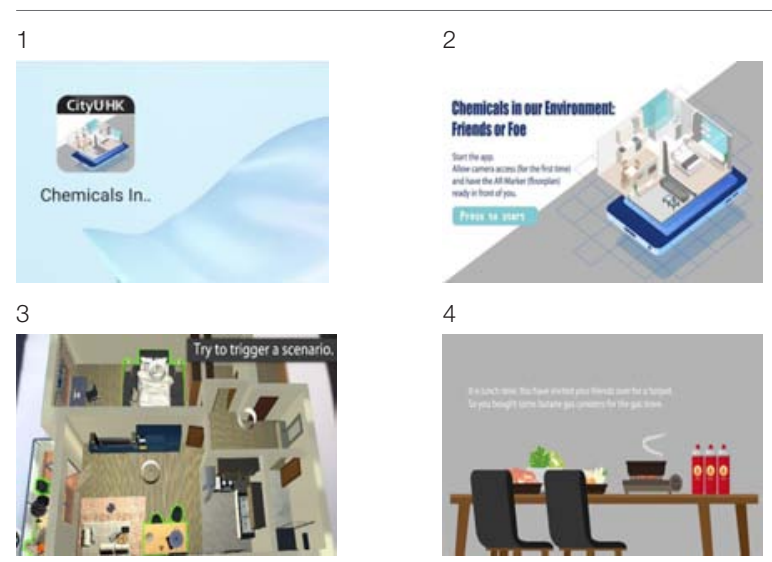

5
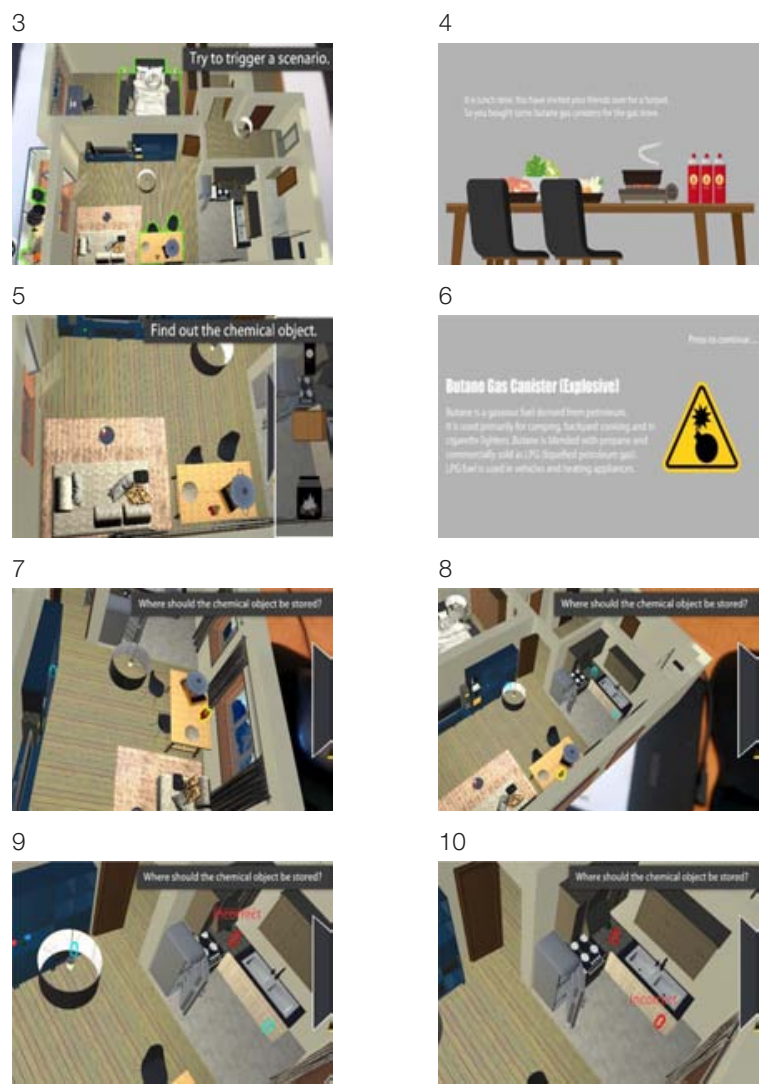

11
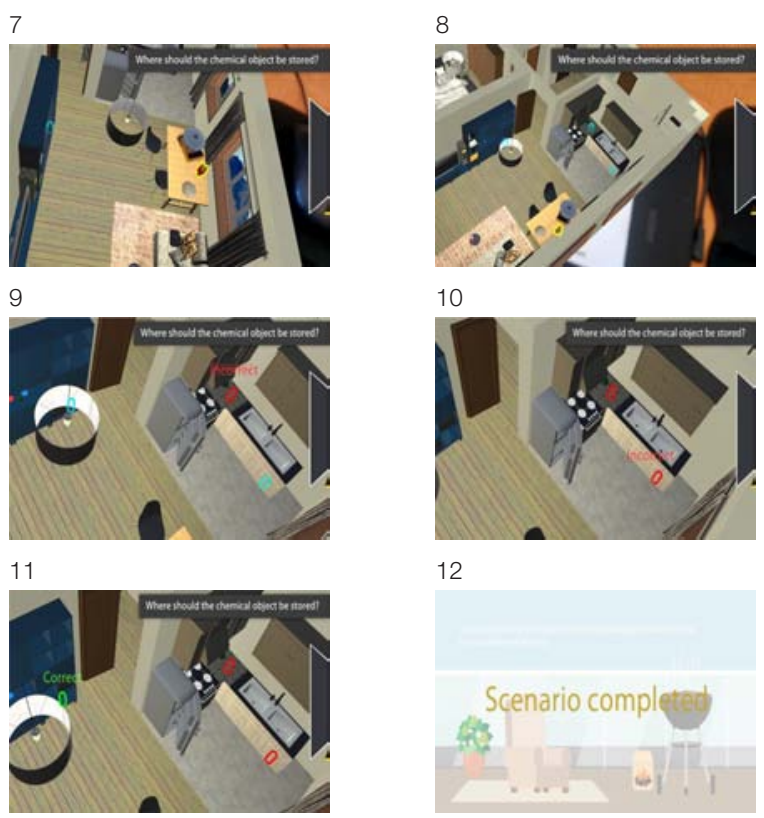

10

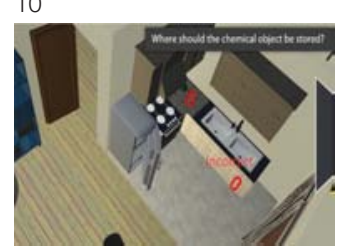

12 was appropriate for undergraduate students, we conducted a reliability analysis. The Cronbach's alpha coefficients for each construct and the entire questionnaire are all over 0.8 , suggesting the questionnaire's high inner consistency and reliability (Table 3 ). Descriptive statistics for each construct and their correlation were calculated and analyzed below.

\section{Descriptive Analysis of Students' Attitude}

The mean score and standard deviation of each construct were summarized in Table 4. The average score of each item of the corresponding construct was calculated. Among the four constructs, cognitive accessibility yields the highest score, 4.72, while cognitive validity has the lowest, 4.01 . These scores may suggest that students were generally satisfied with the AR software's usability, but they would look for more in-depth chemical knowledge.

From the Learning Attitude construct (Table 5), the 3 highest scores items ("I think that learning chemistry is rewarding [4.78]"; "I think that learning things related to chemistry is meaningful [4.76]"; "I think that learning and observing chemistry-related content in addition to that in textbooks is meaningful [4.65]") suggest that most students value the knowledge learned in Chemistry and they prefer a more personal and observable learning experience instead of merely reading Chemistry textbooks. Despite being the lowest score item, the statement "I view learning about the chemicals in an Augmented Reality software as rewarding" still yielded a mean of 4.30 . This may indicate that even though the AR software is a rewarding companion to learn about Chemicals, the design or the content can be further improved to bring a more fruitful experience to learners.

Descriptive statistics for the Satisfaction construct in Table 6 show that students are in favor of the user interface of the software (4.54 in "The color of this software is appropriate, as it is attractive and does not distract me"), the application of science-subject-discipline related AR (4.49 in "I hope that

TABLE 4 | Descriptive statistics for the four questionnaire constructs.

\begin{tabular}{lccccc}
\hline Variable & Sample size & Min & Max & Mean & SD \\
\hline Learning attitude & 37 & 1 & 6 & 4.5483 & 0.9153 \\
Satisfaction & 37 & 1 & 6 & 4.2915 & 1.1611 \\
Cognitive validity & 37 & 1 & 6 & 4.0108 & 1.0884 \\
Cognitive accessibility & 37 & 1 & 6 & 4.7230 & 1.0421
\end{tabular}


TABLE 5 | Descriptive statistics for "learning attitude" construct.

\begin{tabular}{|c|c|c|}
\hline Item & Mean & $S D$ \\
\hline $\begin{array}{l}\text { I view learning about the chemicals in an } \\
\text { Augmented Reality software as rewarding }\end{array}$ & 4.30 & 0.8119 \\
\hline I think that learning chemistry is rewarding & 4.78 & 0.7865 \\
\hline $\begin{array}{l}\text { I think that learning things related to chemistry } \\
\text { is meaningful }\end{array}$ & 4.76 & 0.7229 \\
\hline $\begin{array}{l}\text { I think that learning and observing } \\
\text { chemistry-related content in addition to that in } \\
\text { textbooks is meaningful }\end{array}$ & 4.65 & 0.8887 \\
\hline $\begin{array}{l}\text { I will actively search for information related to } \\
\text { chemistry in books or on the internet }\end{array}$ & 4.49 & 0.9894 \\
\hline $\begin{array}{l}\text { When I come across problems in learning } \\
\text { chemistry, I will actively reach out to teachers, } \\
\text { classmates, books or the internet for solutions }\end{array}$ & 4.51 & 0.9609 \\
\hline $\begin{array}{l}\text { I think that learning chemistry is important for } \\
\text { everyone }\end{array}$ & 4.35 & 1.1357 \\
\hline
\end{tabular}

other disciplines such as Physics and Biology will apply AR tools to learning as well) and gamified learning environment (4.49 in "I like game-like learning methods"). It is expected science students are keener on the AR experience because many science concepts are relatively abstract and cannot be easily observed or experienced personally. The lowest score item, "The AR-based learning tool enables me to learn not only on my own but also with my friends and classmates (3.92)," is also expected since the AR software was used as a remote learning tool during the physical class suspension. This constraint may hinder the exchange or communication among peers during the use of the software.

Results of students' Cognitive Validity are shown in Table 7. The contrast between the highest score item, "I believe that AR demonstration renders learning materials more detailed and understandable (4.35)," and the bottom item, "This AR learning tool is more effective than any other software I have ever used (3.73)," may suggest that students are benefited from the interaction and observation of elements within the AR software. The result met our expectation that the AR learning tool, which integrates the relevant textual and visual information, can reduce the extraneous cognitive load to enhance germane load for a better understanding of the learning materials. Still, the extra setup of AR, which may be novel to students, may, contrarily, pose an unfavorable extraneous load on students hurting AR learning effectiveness.

The Cognitive Accessibility construct (Table 8) receives the highest score among all constructs, indicating that students can master the AR at a reasonable time. The lowest score item, "The content of and procedures for this learning activity are clear and understandable to me (4.43)," may suggest that additional instructions shall be given to students to facilitate a better learning experience and lower cognitive load of AR operation, especially when this is a novel learning experience during the online learning mode.

In summary, the above constructs demonstrate overall positive feedback toward learning attitude and the AR software for the Chemistry class. The findings echoed the idea that immersive learning technology, like AR and VR, can help
TABLE 6 | Descriptive statistics for "satisfaction" construct.

\begin{tabular}{|c|c|c|}
\hline Item & Mean & $S D$ \\
\hline $\begin{array}{l}\text { The AR-based learning software is more } \\
\text { interesting than previously used learning } \\
\text { methods }\end{array}$ & 4.19 & 0.9079 \\
\hline $\begin{array}{l}\text { This game-like learning tool can aid me in } \\
\text { discovering new questions }\end{array}$ & 4.27 & 1.2394 \\
\hline $\begin{array}{l}\text { Using AR-based software enables me to view } \\
\text { chemistry concepts and chemical substances } \\
\text { in a different way }\end{array}$ & 4.38 & 1.0369 \\
\hline I like learning chemistry using AR & 4.19 & 1.2211 \\
\hline I like game-like learning methods & 4.49 & 1.4068 \\
\hline $\begin{array}{l}\text { I hope that other disciplines such as Physics } \\
\text { and Biology will apply AR tools to learning as } \\
\text { well }\end{array}$ & 4.49 & 1.1456 \\
\hline $\begin{array}{l}\text { I hope to use similar AR tools to learn chemistry } \\
\text { in the future if possible }\end{array}$ & 4.27 & 1.1937 \\
\hline $\begin{array}{l}\text { I will recommend the AR learning tool to other } \\
\text { classmates }\end{array}$ & 4.32 & 1.1317 \\
\hline I'm interested in using AR-based learning tools & 4.32 & 1.2031 \\
\hline $\begin{array}{l}\text { The content of this software is closely related to } \\
\text { the course's "chemical substances," which is a } \\
\text { very interesting topic to me }\end{array}$ & 4.24 & 1.2997 \\
\hline $\begin{array}{l}\text { The AR-based learning tool enables me to learn } \\
\text { not only on my own but also with my friends } \\
\text { and classmates }\end{array}$ & 3.92 & 1.1150 \\
\hline $\begin{array}{l}\text { The design of this software is pleasing and } \\
\text { genuine }\end{array}$ & 4.38 & 1.2099 \\
\hline $\begin{array}{l}\text { The color of this software is appropriate, as it is } \\
\text { attractive and does not distract me }\end{array}$ & 4.54 & 0.9005 \\
\hline $\begin{array}{l}\text { I think that learning about the chemical } \\
\text { substances inside and outside the household } \\
\text { using an AR-based learning tool is necessary }\end{array}$ & 4.08 & 1.1874 \\
\hline
\end{tabular}

TABLE 7 | Descriptive statistics for "cognitive validity" construct.

\begin{tabular}{lcc}
\hline Item & Mean & SD \\
\hline $\begin{array}{l}\text { I believe that AR demonstration renders learning } \\
\text { materials more detailed and understandable }\end{array}$ & 4.35 & 0.8887 \\
I think that using this game-like AR learning tool & 4.05 & 1.0787 \\
is very helpful for learning chemistry & & \\
This AR learning tool is more effective than any & 3.73 & 1.1702 \\
other software I have ever used & & \\
$\begin{array}{l}\text { Using this AR software enables me to master } \\
\text { important knowledge points in an in-depth }\end{array}$ & 3.89 & 1.1251 \\
manner and comprehend the principles I did & & \\
not understand in the past & & \\
$\begin{array}{l}\text { The AR learning tool provides abundant space } \\
\text { for me to think and try, which aids me in solving }\end{array}$ & 4.03 & 1.1177 \\
problems & & \\
\end{tabular}

convert some unobservable and abstract concepts in science subjects to interactive learning materials. Consequently, learners can benefit from first-hand interaction to enhance their understanding during the better learning process. Learners are more engaged and motivated to learn with GBL under the flipped classroom context.

The Pearson Correlation coefficient was calculated in Table 9 to evaluate the correlation between students' learning attitudes and AR software perception. Generally, Learning Attitude 
TABLE 8 | Descriptive statistics for "cognitive accessibility" construct.

\begin{tabular}{lcc}
\hline Item & Mean & SD \\
\hline $\begin{array}{l}\text { Operating the AR software is } \\
\text { not difficult }\end{array}$ & 4.73 & 1.0179 \\
$\begin{array}{l}\text { Learning to use this AR tool } \\
\text { does not cost me a great deal } \\
\text { of time and energy }\end{array}$ & 4.92 & 0.8293 \\
$\begin{array}{l}\text { The content of and procedures } \\
\text { for this learning activity are clear } \\
\text { and understandable to me }\end{array}$ & 4.43 & 1.2143 \\
$\begin{array}{l}\text { I can grasp how to operate AR } \\
\text { software within a very short }\end{array}$ & & \\
timeframe & 4.81 & 1.0498 \\
\end{tabular}

TABLE 9 | Pearson correlations between "learning attitude" and "satisfaction," "cognitive validity," "cognitive accessibility".

\begin{tabular}{lcccc}
\hline & $\begin{array}{c}\text { Learning } \\
\text { attitude }\end{array}$ & Satisfaction & $\begin{array}{c}\text { Cognitive } \\
\text { validity }\end{array}$ & $\begin{array}{c}\text { Cognitive } \\
\text { accessibility }\end{array}$ \\
\hline Learning attitude & & 0.443 & 0.412 & 0.272 \\
Satisfaction & 0.443 & & 0.011 & 0.103 \\
Cognitive validity & 0.006 & & & \\
& 0.412 & & & \\
Cognitive accessibility & 0.011 & & & \\
& 0.272 & & & \\
& 0.103 & & & \\
\hline
\end{tabular}

positively correlates with students' positive feedback toward the AR software, ranging from 0.412 to $0.443, \mathrm{p}<0.05$, except for the construct Cognitive Accessibility with 0.272, $p=0.103$. This high $p$-value in Cognitive Accessibility may not necessarily imply its insignificance with Learning Attitude. Still, it may be regarded as an indicator to further consider the variation of learners' technology adeptness and accessibility when carrying out novel learning activities, especially in the context of distant online learning. In summary, the results reflect that students who perceive a higher value in learning Chemistry generally demonstrate greater satisfaction and usefulness toward the AR software of the Chemistry class.

\section{Students' Comments Toward the AR Software}

The optional open-ended question asking for students' comments on the AR software at the end of the questionnaire collected 12 valid responses. According to the comments, 11 out of the 12 replies showed a positive appreciation for the AR software, and they thought it was fun and interactive to learn Chemistry via the AR software. The only negative response suggested that more interactions in the AR software were preferable. Two of the answers suggested more content should be added to enrich the learning process. At the same time, 1 student agreed that learning through AR was fun but might be less effective than reading books or searching online for domestic chemicals. Additionally, there were 2 replies concerning the difficulties of the AR operations.

\section{DISCUSSION AND CONCLUSION}

The questionnaire results show that students generally had a positive evaluation and satisfaction toward the AR software because it allows easy observation and manipulation of real-world environments or elements. Students appreciated the AR software as a valuable tool in a flipped classroom context, allowing them to better prepare and deeper understand the intended learning outcomes before faceto-face online classes. Based on the findings from the questionnaire and students' comments, students were looking for more content, better control, and a nicer presentation of the AR software in order to enhance their satisfaction with it, thus suggesting possible improvements for future works.

Furthermore, significant positive correlations between Learner Attitude and perception of the AR software were found. Despite the high $p$-value in the construct of Cognitive Accessibility, its score was still within the positive category but may bring an implication for further consideration during the design and introduction of the software to minimize students' overhead to access the AR. This result also aligns with Cai et al. (2014)'s conclusion that promoting learner's initiative toward Chemistry is the cornerstone to enhance learning effectiveness via the AR software. Since this is only the first phase of the project, there are many limitations. The team is working on a content expansion for the AR app to cover a minimum of 10 sets of scenarios in the second phase. Further research can be extended when the AR app is launched publicly to cover more Chemistry classes in Hong Kong after this pilot study. Future research may also include secondary students to investigate the impact of the study.

\section{Possible Improvements for Future Work}

The paper's findings have proven great potentials for $A R$ software as a pre-class companion under the context of a flipped classroom. The comments from the students suggest several possible improvements:

- Add more scenes in the AR software. Insufficient content may undermine students' positive perceptions of the AR software.

- Add more gaming elements and interactions. Students showed positive responses to the game-like learning methods, while the limits of interaction among the virtual objects in the AR may reduce their experience in the software. More interactions under the gamified AR environment may allow a better immersive learning experience, which may facilitate effective learning.

- Provide better instructions and training on the use of AR software. Extra instructional videos of the setup and instant response to the difficulties encountered during the setup may help students increase their technological capabilities and access to AR, which may allow them to focus and appreciate more on the content and knowledge in the AR software. 
The positive results of the AR software also encourage some possible future research directions:

- Expand the sample size to cover more Chemistry students in secondary schools and universities in Hong Kong to boost the impact of the research.

- Evaluate the effectiveness of the AR software in terms of pre- and post-tests' results. Due to time limitations, this research has not collected any test results before and after using the AR software. Future research can focus on the effectiveness of using this AR software by analyzing users' academic performance.

- Add a control group to compare the effectiveness of the AR software and other learning methods. Even though $\mathrm{AR}$ is generally regarded as a powerful tool for $3 \mathrm{D}$ structure comprehension and experience, it cannot be considered to be a one-size-fits-all solution for all students with different learning styles. It would be valuable to compare the effectiveness of the AR software and other learning methods.

- Evaluate the user interface and the control of the AR software. Due to the hardware limitations, it is understandable that several students found control within AR unsatisfactory. Future human-computer interaction (HCI) research may shed light on aiding such a negative experience.

\section{Technical Notes}

There are overwhelming AR toolkits, either proprietary or opensourced, available on the market, providing different feature sets under various licenses, which may not be familiar with researchers. Hence, it is necessary to fully evaluate those licenses before publishing, especially when the product is intended to be published publicly. Even though open-sourced toolkits may solve licensing concerns, researchers shall also take whether there are sufficient resources and support of the toolkit, e.g., the completeness of documentation and the presence of a discussion forum, into consideration.

Furthermore, AR applications on smartphones provide a convenient and minimized setup solution to appreciate AR in an educational context. However, the mainstream mobile operating systems' incompatibilities impose a great deal of development overhead for cross-platform programming. Such factors are more significant when there are different specifications among Android smartphones. Researchers are suggested to carry out UAT on various phones with various specifications.

Publishing the AR app to the platform-specific market stores can minimize the technical problems during installation.

\section{REFERENCES}

Abdoli-Sejzi, A., and Bahru, J. (2015). Augmented reality and virtual learning environment. J. Appl. Sci. Res. 11, 1-5.

Akçayır, M., and Akçayır, G. (2017). Advantages and challenges associated with augmented reality for education: a systematic review of the literature. Educ. Res. Rev. 20, 1-11. doi: 10.1016/j.edurev.2016. 11.002
However, different public publishing requirements and code reviews among platforms require exhaustive effort. Researchers are suggested to evaluate the necessity of publishing the app publicly and make thorough preparations in advance.

\section{DATA AVAILABILITY STATEMENT}

The original contributions presented in the study are included in the article/supplementary material, further inquiries can be directed to the corresponding author/s.

\section{ETHICS STATEMENT}

The studies involving human participants were reviewed and approved by the City University of Hong Kong Research Committee. The patients/participants provided their written informed consent to participate in this study.

\section{AUTHOR CONTRIBUTIONS}

$\mathrm{AL}$ was the principal author of the article and co-investigator of the project, responsible for instructional designs of the AR, and flipped learning and drafting of the article. CW was the project leader who contributed to the article's main ideas and structure. RC was the instructor of the Chemistry class for the AR experiment, provided expertise of the subject and the content of the AR design, and responsible for carrying out the survey in the study. TI was the co-investigator of the project and provided essential cross-departmental coordination during the development and the teaching process. All authors contributed to the article and approved the submitted version.

\section{FUNDING}

The AR app illustrated in the manuscript was developed by the City University of Hong Kong for a year four undergraduate Chemistry course under CityU's Teaching Development Grant and 2 UGC's project funds, namely (i) Developing Multidisciplinary and Multicultural Competences through Gamification and Challenge-based Collaborative Learning, and (ii) Effective Implementation of the Flipped Classroom Approach in Hong Kong Higher Education for Enhanced Learning Outcome. Environ. 6, 355-385. doi: 10.1162/pres.1997.6.4.355

Behmke, D. A., Brannock, E., Kerven, D., Lutz, R., Paredes, J., Pennington, R., et al. (2019). "AR chemistry: an undergraduate, technology-based research and development initiative to incorporate AR molecular models in the chemistry curriculum," in Technology Integration in Chemistry Education and Research (TICER), eds T. Gupta, and R. E. Belford (Washington, DC: American Chemical Society), 53-64. 
Bower, M., and Jong, M. S. Y. (2020). Immersive virtual reality in education. Br. J. Educ. Technol. 51, 1981-1990. doi: 10.1111/bjet.13038

Brom, C., Šisler, V., and Slavík, R. (2010). Implementing digital game-based learning in schools: augmented learning environment of 'Europe 2045'. Multimed. Syst. 16, 23-41.

Cai, S., Wang, X., and Chiang, F.-K. (2014). A case study of augmented reality simulation system application in a chemistry course. Comput. Hum. Behav. 37, 31-40. doi: 10.1016/j.chb.2014.04.018

Chang, S.-C., and Hwang, G.-J. (2018). Impacts of an augmented reality-based flipped learning guiding approach on students' scientific project performance and perceptions. Comput. Educ. 125, 226-239. doi: 10.1016/j.compedu.2018.06. 007

Chao, K.-H., Chang, K.-E., Lan, C. H., Kinshuk, and Sung, Y.-T. (2016). Integration of mobile AR technology in performance assessment. J. Educ. Technol. Soc. 19, 239-251.

Chen, C.-M., and Tsai, Y.-N. (2012). Interactive augmented reality system for enhancing library instruction in elementary schools. Comput. Educ. 59, 638652. doi: 10.1016/j.compedu.2012.03.001

Cheng, K.-H. (2016). Reading an augmented reality book: an exploration of learners' cognitive load, motivation, and attitudes. Australas. J. Educ. Technol. 33, 53-69. doi: 10.14742/ajet.2820

Cheng, K.-H., and Tsai, C.-C. (2013). Affordances of augmented reality in science learning: suggestions for future research. J. Sci. Educ. Technol. 22, 449-462. doi: 10.1007/s10956-012-9405-9

Childs, P. E., Hayes, S. M., and O'dwyer, A. (2015). "Chemistry and everyday life: relating secondary school chemistry to the current and future lives of students," in Relevant Chemistry Education, eds I. Eilks, and A. Hofstein (Rotterdam: Brill Sense), 33-54.

Craik, F. I. M., and Lockhart, R. S. (1972). Levels of processing: a framework for memory research. J. Verbal Learn. Verbal Behav. 11, 671-684. doi: 10.1016/ S0022-5371(72)80001-X

Crocco, F., Offenholley, K., and Hernandez, C. (2016). A proof-of-concept study of game-based learning in higher education. Simul. Gaming 47, 403-422. doi: $10.1177 / 1046878116632484$

Dede, C. (2008). "Theoretical perspectives influencing the use of information technology in teaching and learning," in International Handbook of Information Technology in Primary and Secondary Education, eds J. Voogt, and G. Knezek (Boston, MA: Springer), 43-62.

Eck, R. V. (2006). Digital game-based learning: it's not just the digital natives who are restless. Educ. Rev. 41, 16-30.

Fred, P., Alexander, R., and John, S. (2004). Cognitive load theory: instructional implications of the interaction between information structures and cognitive architecture. Instr. Sci. 32, 1-8. doi: 10.1023/B:TRUC.0000021806.17516.d0

Gee, J. P. (2008). Learning and Games. Chicago, IL: MacArthur Foundation Digital Media and Learning Initiative.

Guttentag, D. A. (2010). Virtual reality: applications and implications for tourism. Tour. Manag. 31, 637-651. doi: 10.1016/j.tourman.2009.07.003

Herrington, A., Herrington, J., and Mantei, J. (2009). "Design principles for mobile learning," in New Technologies, New Pedagogies: Mobile Learning in Higher Education, eds J. Herrington, A. Herrington, J. Mantei, I. Olney, and B. Ferry (Wollongong, NSW: University of Wollongong), 129-138.

Hirumi, A., Appelman, B., Rieber, L., and van Eck, R. (2010). Preparing instructional designers for game-based learning: part 2. Techtrends 54, 19-27. doi: 10.1007/s11528-010-0416-1

Hwang, G.-J., Lai, C.-L., and Wang, S.-Y. (2015). Seamless flipped learning: a mobile technology-enhanced flipped classroom with effective learning strategies. J. Comput. Educ. 2, 449-473. doi: 10.1007/s40692-015-0043-0

Ibáñez, M.-B., and Delgado-Kloos, C. (2018). Augmented reality for STEM learning: a systematic review. Comput. Educ. 123, 109-123. doi: 10.1016/j. compedu.2018.05.002

Im, S. W. T., Chiu, P. H. P., Shek, C. H., Ng, M., and Li, L. (2018). "Using virtual reality to enhance learning in a Chinese architectures course: a flipped classroom approach," in Proceedings of the 2018 IEEE International Conference on Teaching, Assessment, and Learning for Engineering (TALE), Wollongong, NSW, 624-629.

Ip, H. H. S., Li, C., Wong, Y. W., Leoni, S., Ma, K. F., Wong, H. T., et al. (2016). "Delivering immersive learning experience for massive open online courses (MOOCs)," in Proceedings of the 15th International Conference Advances in
Web-Based Learning - ICWL 2016 Lecture Notes in Computer Science, eds U. Nanni, M. Temperini, M. Spaniol, D. K. W. Chiu, and I. Marenzi (Cham: Springer International Publishing), 112-117.

Jensen, S. A. (2011). In-Class versus online video lectures:similar learning outcomes, but a preference for in-class. Teach. Psychol. 38, 298-302. doi: 10. $1177 / 0098628311421336$

Joe, K. (2015). Three-dimensional instruction: using a new type of teaching in the science classroom. Sci. Child. 53, 6-8. doi: 10.2505/4/sc15_053_03_6

Johnson, L., Adams Becker, S., Cummins, M., Estrada, V., Freeman, A., and Hall, C. (2016). NMC Horizon Report: 2016 Higher Education Edition. Austin, TX: The New Media Consortium.

Karukstis, K. K., and van Hecke, G. R. (2003). Chemistry Connections: The Chemical Basis of Everyday Phenomena. Amsterdam: Elsevier.

Kerawalla, L., Luckin, R., Seljeflot, S., and Woolard, A. (2006). "Making it real": exploring the potential of augmented reality for teaching primary school science. Virtual Real. 10, 163-174.

Khan, T., Johnston, K., and Ophoff, J. (2019). The impact of an augmented reality application on learning motivation of students. Adv. Hum. Comput. Interact. 2019:7208494. doi: 10.1155/2019/7208494

Kiili, K. (2005). Digital game-based learning: towards an experiential gaming model. Internet High. Educ. 8, 13-24. doi: 10.1016/j.iheduc.2004.12.001

Kobayashi, K. D. (2017). Using flipped classroom and virtual field trips to engage students. Horttechnology 27, 458-460. doi: 10.21273/horttech03350-17

Koutromanos, G., and Styliaras, G. (2015). "The buildings speak about our city": a location based augmented reality game," in Proceedings of the 2015 6th International Conference on Information, Intelligence, Systems and Applications (IISA), (Piscataway, NJ: IEEE), 1-6.

Kundu, S. N., Muhammad, N., and Sattar, F. (2017). "Using the augmented reality sandbox for advanced learning in geoscience education," in Proceedings of the 2017 IEEE 6th International Conference on Teaching, Assessment, and Learning for Engineering (TALE), (Piscataway, NJ: IEEE), 13-17.

Kurilovas, E. (2016). Evaluation of quality and personalisation of VR/AR/MR learning systems. Behav. Inform. Technol. 35, 998-1007. doi: 10.1080/0144929X. 2016.1212929

Lave, J. (1991). Situated Learning: Legitimate Peripheral Participation. Cambridge: Cambridge University Press.

Limniou, M., Roberts, D., and Papadopoulos, N. (2008). Full immersive virtual environment CAVETM in chemistry education. Comput. Educ. 51, 584-593. doi: 10.1016/j.compedu.2007.06.014

Lin, H.-F., and Chen, C.-H. (2015). Design and application of augmented reality query-answering system in mobile phone information navigation. Expert Syst. Appl. 42, 810-820. doi: 10.1016/j.eswa.2014.07.050

Lo, C. K. (2018). Grounding the flipped classroom approach in the foundations of educational technology. Educ. Technol. Res. Dev. 66, 793-811. doi: 10.1007/ s11423-018-9578- $\mathrm{x}$

Lu, S.-J., and Liu, Y.-C. (2015). Integrating augmented reality technology to enhance children's learning in marine education. Environ. Educ. Res. 21, 525541. doi: 10.1080/13504622.2014.911247

Martín-Gutiérrez, J., Luís Saorín, J., Contero, M., Alcañiz, M., Pérez-López, D. C., and Ortega, M. (2010). Design and validation of an augmented book for spatial abilities development in engineering students. Comput. Graph. 34, 77-91. doi: 10.1016/j.cag.2009.11.003

Mayer, R. E. (2009). Multimedia Learning. Cambridge: Cambridge University Press.

Milgram, P., Takemura, H., Utsumi, A., and Kishino, F. (1995). "Augmented reality: a class of displays on the reality-virtuality continuum," in SPIE Proceedings on Telemanipulator and Telepresence Technologies, (Bellingham, WA: SPIE).

Naismith, L., Lonsdale, P., Vavoula, G. N., and Sharples, M. (2004). Mobile Technologies and Learning. Bristol: Futurelab.

Pence, H. E. (2010). Smartphones, smart objects, and augmented reality. Ref. Libr. 52, 136-145. doi: 10.1080/02763877.2011.52 8281

Röhl, A., Reddy, S., and Shannon, G. J. (2013). The flipped classroom: an opportunity to engage millennial students through active learning strategies. J. Fam. Consum. Sci. 105, 44-49.

Shirazi, A., and Behzadan, A. (2013). "Assessing the pedagogical value of augmented reality-based learning in construction engineering," in Proceedings 
of the 13th International Conference on Construction Applications of Virtual Reality (CONVR), (London: Citeseer).

Sommerauer, P., and Müller, O. (2018). "Augmented reality for teaching and learning-a literature review on theoretical and empirical foundations," in Proceedings of the 26th European Conference on Information Systems: Beyond Digitization - Facets of Socio-Technical Change, ECIS 2018, Portsmouth.

Sotiriou, S., and Bogner, F. X. (2008). Visualizing the invisible: augmented reality as an innovative science education scheme. Adv. Sci. Lett. 1, 114-122.

Squire, K. D., and Jan, M. (2007). Mad City mystery: developing scientific argumentation skills with a place-based augmented reality game on handheld computers. J. Sci. Educ. Technol. 16, 5-29. doi: 10.1007/s10956-006-9037-z

Sweller, J. (2011). "Cognitive load theory," in Psychology of Learning and Motivation, eds J. P. Mestre, and B. H. Ross (San Diego, CA: Elsevier), 37-76.

Sweller, J., and Chandler, P. (1994). Why some material is difficult to learn. Cogn. Instr. 12, 185-233. doi: 10.1207/s1532690xci1203_1

Tosti, H. C. C., Stephen, J. H. Y., and Gwo-Jen, H. (2014). An augmented realitybased mobile learning system to improve students' learning achievements and motivations in natural science inquiry activities. Educ. Technol. Soc. 17, 352-365.

van Gog, T., Paas, F., and Sweller, J. (2010). Cognitive load theory: advances in research on worked examples, animations, and cognitive load measurement. Educ. Psychol. Rev. 22, 375-378. doi: 10.1007/s10648-010-9145-4

van Merriënboer, J. J. G., and Sweller, J. (2005). Cognitive load theory and complex learning: recent developments and future directions. Educ. Psychol. Rev. 17, 147-177. doi: 10.1007/s10648-005-3951-0

Wang, F., and Hannafin, M. J. (2005). Design-based research and technologyenhanced learning environments. Educ. Technol. Res. Dev. 53, 5-23.

Wong, C. S. K., Lu, A., Im, T. S. W., and Cheung, R. Y. H. (2019). "Supporting flipped learning with virtual-reality field trips," in Proceedings of the 2019
International Symposium on Educational Technology (ISET), Hradec Kralove, 54-59.

Woolfolk, A., and Hoy, A. W. (2006). Educational Psychology. Boston, MA: Allyn \& Bacon, Incorporated.

Wu, H.-K., Lee, S. W.-Y., Chang, H.-Y., and Liang, J.-C. (2013). Current status, opportunities and challenges of augmented reality in education. Comput. Educ. 62, 41-49. doi: 10.1016/j.compedu.2012.10.024

Yoon, S., Anderson, E., Lin, J., and Elinich, K. (2017). How augmented reality enables conceptual understanding of challenging science content. J. Educ. Technol. Soc. 20, 156-168.

Yung, R., and Khoo-Lattimore, C. (2019). New realities: a systematic literature review on virtual reality and augmented reality in tourism research. Curr. Issues Tour. 22, 2056-2081. doi: 10.1080/13683500.2017.14 17359

Zhang, J., Sung, Y.-T., Hou, H.-T., and Chang, K.-E. (2014). The development and evaluation of an augmented reality-based armillary sphere for astronomical observation instruction. Comput. Educ. 73, 178-188. doi: 10.1016/j.compedu. 2014.01.003

Conflict of Interest: The authors declare that the research was conducted in the absence of any commercial or financial relationships that could be construed as a potential conflict of interest.

Copyright (c) $2021 \mathrm{Lu}$, Wong, Cheung and Im. This is an open-access article distributed under the terms of the Creative Commons Attribution License (CC BY). The use, distribution or reproduction in other forums is permitted, provided the original author(s) and the copyright owner(s) are credited and that the original publication in this journal is cited, in accordance with accepted academic practice. No use, distribution or reproduction is permitted which does not comply with these terms. 